\title{
Leisure Time Sports Activities and Life Satisfaction: Deeper Insights Based on a Representative Survey from Germany
}

\author{
Michael Mutz ${ }^{1}$ (D) Anne K. Reimers ${ }^{2} \cdot$ Yolanda Demetriou $^{3}$
}

Received: 1 May 2020 / Accepted: 1 September 2020 / Published online: 12 September 2020

(C) The Author(s) 2020

\begin{abstract}
Observational and experimental studies show that leisure time sporting activity (LTSA) is associated with higher well-being. However, scholars often seem to assume that 1) LTSA fosters "general" life satisfaction, thereby ignoring effects on domain satisfaction; 2) the effect of LTSA on well-being is linear and independent of a person's general activity level; 3 ) the amount of LTSA is more important than the repertoire of LTSA, i.e. the number of different activities; 4) all kinds of LTSA are equal in their effects, irrespective of spatial and organisational context conditions. Using data from the German SALLSA-Study ("Sport, Active Lifestyle and Life Satisfaction"), a large-scale CAWI-Survey $(N=1008)$ representing the population $\geq 14$ years, the paper takes a closer look on these assumptions. Findings demonstrate that LTSA is associated with general life satisfaction and domain-specific satisfaction (concerning relationships, appearance, leisure, work and health), but that the relationship is most pronounced for leisure satisfaction. Associations of sport with life satisfaction, leisure satisfaction and subjective health are non-linear, approaching an injection point from which on additional LTSA is no longer beneficial. Moreover, findings lend support to the notion that diversity in LTSA matters, as individuals with higher variation in sports activities are more satisfied. Finally, results with regard to spatial and organizational context suggest that outdoor sports and club-organized sports have additional benefits.
\end{abstract}

Keywords Well-being $\cdot$ Quality of life $\cdot$ Physical activity $\cdot$ Exercise $\cdot$ Health

Michael Mutz

michael.mutz@sport.uni-giessen.de

1 Institute of Sport Science, Justus-Liebig-University Giessen, Giessen, Germany

2 Department of Sport Science and Sport, Friedrich-Alexander-University of Erlangen-Nuremberg, Nuremberg, Germany

3 Department of Sport and Health Sciences, Technical University of Munich, Munich, Germany 


\section{Introduction}

Sports, exercise and physical activity have become major issues in well-being research over recent years. Previous studies have consistently shown that physical activity is, amongst others, positively associated with happiness, health-related quality of life and satisfaction with life (e.g., Brown et al. 2015; Dolan et al. 2014; Höner and Demetriou 2012; Huang and Humphreys 2012; Richards et al. 2015; Sigvartsen et al. 2016). Positive links between physical activity and well-being were found in all age groups, including youths (McMahon et al. 2017), students (Jetzke and Mutz 2019), adults (Downward and Dawson 2016; Marques et al. 2016) and the elderly (Lera-López et al. 2017). Recent reviews based on observational and intervention studies (Wiese et al. 2018; White et al. 2017; Zhang and Chen 2019) conclude that even small amounts of additional physical activity lead to significant increases in wellbeing.

Physical activities during leisure time, i.e. in freely disposable time, have a greater potential to affect well-being positively compared to activities in workor transport-related domains (Hamer et al. 2009; White et al. 2017). Particularly sport and exercise constitute the core area of leisure time physical activity. Sport and exercise both refer to planned and structured activities that involve physical exertion, but sport additionally is usually rules-based and often has a competitive character (Giulianotti 2005).

Notwithstanding the fact that leisure time sports and exercise activities (LTSA) are associated with well-being, few studies have tried to provide a more nuanced picture by differentiating effects according to types of activity, activity settings, intensity levels, or sporting motivations. In a cross-sectional study, Dolan et al. (2014) show that the frequency of exercise and playing sports positively correlates with satisfaction with life, but that the effect is higher among individuals who exercise for "pleasure". Downward and Dawson (2016) found that sporting activities with a lower intensity (likely to be of a casual recreational nature) are associated with higher overall levels of well-being compared to high-intensity exercise. Jetzke and Mutz (2019) demonstrate that intrinsically motivated sporting activities have a greater effect on well-being. Hence, doing sports for "enjoyment" or "to feel fit" add more to a person's well-being than doing sports for "losing or controlling weight".

From a sports science perspective key questions regarding the link between LTSA and well-being are still unanswered: First, studies have not adequately addressed the links between LTSA and domain-specific satisfaction: Which life domains do sporting activities affect and which not? Second, the linearity assumption is challenged, i.e. that additional amounts of sports activity have a beneficial effect on well-being, irrespective of a person's initial activity level. Third, it is questionable whether the diversity in LTSA matters: Is a broader repertoire of sporting activities associated with higher life satisfaction? And finally, until now it remains unclear whether the spatial and organizational context (e.g., activities in sports clubs, indoor/outdoor activities) have a moderating effect on the relationship between LTSA and life satisfaction. 


\section{State of Research and Research Questions}

\section{LTSA, General Life Satisfaction and Domain-Specific Satisfaction}

On a conceptual level, life satisfaction ratings are supposed to be based on a cognitive judgement process (Diener 1984; Schimmack 2008). In this judgement process people reflect on accessible information about their lives that are relevant for quality of life, like living conditions, social relations or job satisfaction. According to bottom-up theories of life satisfaction, individuals evaluate the most relevant single domains of their life, which are then integrated into an overall rating of satisfaction (Diener 1984; Headey 2014). Social and individual differences may exist in the relative weight that a particular life domain has for a person's overall life satisfaction. For instance, it can be presumed that job satisfaction is irrelevant for retired people, but usually of high importance for individuals in employable age. Health satisfaction could be more important for the elderly compared to youths, who may perceive themselves to be less vulnerable to various illnesses. Overall life satisfaction should thus represent a weighted average of domain-specific satisfaction ratings. Although scholars have also pointed to the limits of a bottom-up approach, stating that people may have a general feeling of happiness in first place, which then affects domain-specific satisfaction evaluations in a top-down process (Diener 1984), the bottom-up concept remains popular and has received considerable empirical support (Kuykendall et al. 2015).

In line with such a bottom-up perspective scholars have argued that singular positive leisure experiences first increase satisfaction in leisure life and then generalize to a person's satisfaction with life as a whole (Newman et al. 2014; Sirgy et al. 2017). Compared to other leisure activities, sport is among the most important predictors of leisure satisfaction and equally associated with affective and cognitive dimensions of well-being (Schulz et al. 2018). Scholars claimed that the well-being effect of sporting activities results from the fact that sport satisfies psychological needs, for instance, a need for relatedness, mastery experiences, or autonomy (Sirgy et al. 2017). Some sports may also provide challenging, stimulating and exciting situations, accompanied by affective states like enjoyment, rush or flow, whereas others trigger relaxation or pleasant forms of exhaustion. In any case, individuals usually reflect positively on their experiences during sports (Wienke and Jekauc 2016). LTSA is thus supposed to add to a person's leisure satisfaction and satisfaction with this specific domain could in turn foster general life satisfaction.

Although previous studies and reviews (Kuykendall et al. 2015) suggest that the effect of leisure activities on life satisfaction is mediated by satisfaction with the leisure domain, it is still likely that sports activities also affect satisfaction in other life domains beyond leisure. For instance, if sport enhances a person's sense of belonging and integration, this could boost satisfaction with social relationships. Moreover, Frederick et al. (2016) have shown that body and appearance satisfaction contributes to life satisfaction. Hence, in case that people actively involved in LTSA are more satisfied with their appearance they may also rate their life better. With regard to job satisfaction, a Canadian employee study demonstrated that positive emotional spillover effects from LTSA to work exist (Hecht and Boies 2009). Hence, positive emotions, vitality and energy established during LTSA can be transferred to different life domains, thereby positively affecting domain satisfaction. In view of these 
considerations, a first question arises addressing the domain-specificity of the LTSA effect on satisfaction ratings: Does LTSA solely affect leisure satisfaction and - to a lesser degree - also general life satisfaction or do LTSA effects occur in a wider range of life domains as, for instance, satisfaction with work, appearance, social relations and health?

\section{(Non-)Linearity Assumptions}

With few exceptions, previous research has (more or less implicitly) assumed that LTSA affects well-being in a linear way, i.e. that any sports-related increase in life satisfaction is equally positive regardless of the amount of sport a person is already pursuing (e.g., Richards et al. 2015). However, this assumption is far from being plausible for a number of reasons: Leisure life can become one-sided when the focus on sports activities is too narrow and the amount of time invested in sports too high. This can come at the cost of other leisure pursuits and can negatively affect variation in leisure life. Varied leisure pursuits predict leisure satisfaction (Kuykendall et al. 2015), hence a too time-consuming involvement in LTSA can have a detrimental effect on well-being. Moreover, excessive loads of exercise can lead to overexertion, insufficient recovery, fatigue and injuries (Kellmann et al. 2018). In such cases, the dosage of LTSA is obviously no longer beneficial for a person's well-being.

Health research also suggests that a ceiling effect of sports exists with regard to health outcomes. Based on large-scale US American data, Arem et al. (2015) found that the risk of mortality decreases when individuals perform the recommended minimum amount of physical activity (compared to inactive individuals). The risk of mortality further decreases with additional physical activity until it reaches a ceiling, approximately at an activity level exceeding the recommended minimum by 3 to 5 times. In accordance with these findings, the "extreme exercise hypothesis" (Eijsvogels et al. 2018) postulates that when exercise is performed excessively or for extended periods it adversely affects cardiovascular health. This hypothesis has also been applied to psychological health outcomes such as positive and negative affect and well-being: For instance, Costigan et al. (2019) found a curvilinear relationship between time spent in vigorous physical activity and affect in adolescents.

In view of these findings, it seems plausible that the well-being effect of sports reaches an upper ceiling from which on any further increase in sports activity has only a marginal or even a negative effect on life satisfaction. However, until now few studies addressed this issue with regard to LTSA. Hence, our second research question addresses this void: Does the supposed LTSA effect on life satisfaction and domainspecific satisfaction decrease (and maybe turn to negative) with rising LTSA levels?

\section{Diversity of LTSA and Well-Being}

Only a handful of studies on the relationship of leisure activities and well-being have taken "leisure diversity" or "leisure repertoire" into account. Both concepts refer to the number of different activities that individuals pursue in their leisure-time (Stalker 2011). A higher diversity in leisure activities can possibly lead to a broader range of positive experiences during leisure and to more diversified social contacts. In their 
theorizing, Elias and Dunning (1986) argued that individuals in modern societies developed a deeply rooted need for excitement and stimulation, mostly because modern work-life has become highly routinized, rationalized and formalized with few opportunities to behave spontaneously and to experience or express intense emotions. Individuals thus search for diversion and relief from the monotony of professional life in their leisure time. This need for excitement is supposed to be a key motive for recreational activities.

Previous research has shown that people with greater diversity in leisure activities report lower levels of boredom (Iso-Ahola and Weissinger 1990) and higher levels of happiness (Baker et al. 2005). Survey data from Taiwan indicate that more diverse leisure activities are associated with a smaller risk of depression and higher levels of well-being in older adults (Lee et al. 2018a, b). A large-scale study in deprived neighborhoods in the UK showed that greater diversity of physical activity (i.e., activities in different domains like household, occupation, active travel, leisure and sport) is associated with better mental well-being (Mason et al. 2016). However, studies on LTSA have not yet build upon these considerations, although it seems plausible that a higher diversity in LTSA, i.e. involvement in different types of sport, is associated with additional benefits in terms of well-being. Hence, another research question reads: Does a higher diversity in LTSA relate to higher levels of life satisfaction and domain satisfaction?

\section{Indoor/Outdoor LTSA and Well-Being}

Moreover, recently several studies have focused on the links between well-being and physical activity in the presence of nature, known as green exercise (Lahart et al. 2019; Mnich et al. 2019; Thompson Coon et al. 2011). Previous research has demonstrated that exposure to nature can improve people's health and well-being (Hartig et al. 1991), and this has led to suggestions that performing green exercise may have additional benefits beyond those experienced when being physically active indoors. In a systematic review, Thompson Coon et al. (2011) compared exercising indoors with exercising in natural environments. Green exercise was associated with greater feelings of revitalization and positive engagement, decreases in tension, confusion, anger, depression and increased energy. Participants also reported greater enjoyment and satisfaction with outdoor activity and declared a greater intent to repeat the activity in future. In a more recent systematic review including 28 trials, Lahart et al. (2019) found that compared with indoor exercise, acute bouts of outdoor green exercise may favorably influence mood and enjoyment, but not emotion, perceived exertion, exercise intensity and biological markers. Finally, in their review including 11 studies that examine the psychosocial and physiological outcomes of green exercise in children and adolescents Mnich et al. (2019) conclude that green exercise does not have deleterious effects for children and adolescents and might even be beneficial. Nevertheless, due to the studies' heterogeneity and quality, they were reluctant to provide a definite conclusion based on the current research. In addition, studies evaluating outdoor and adventure programs (e.g., Mutz and Müller 2016; Schell et al. 2012) that include sporting activities in natural environments (e.g., hiking or canoeing) found positive effects for a variety of mental health indicators (e.g., mood, self-esteem, life satisfaction). 
Hence, research in general suggests that LTSA in natural environments has more potential to benefit an individual's well-being than indoor LTSA. Exposure to nature, sunlight and fresh air seemingly has direct psychophysiological impacts related to recovery and well-being. Kaplan (1992) further claimed that interactions with nature are "restorative experiences", because they take people away from daily routines and preexisting conceptions of the world. Another research question thus reads: Does outdoor LTSA relate to higher levels of life satisfaction and domain satisfaction compared to indoor LTSA?

\section{Organizational Setting of LTSA}

Finally, the organizational setting of LTSA could be a potential moderator of any wellbeing effect. At least in Germany, a high share of LTSA takes place in organized settings, usually in sports clubs and fitness studios. Sports clubs are voluntary associations, who offer a large variety of sports on a not-for-profit base. Particularly team sports are highly popular in German sports clubs, with football alone reaching out to more than 7.1 million club members (German Football Association 2019). Research has demonstrated that participation in community sports clubs fosters sense of belonging and affiliation (Hoye et al. 2012) and the social network of acquaintances is larger among sports club members compared to those exercising outside of sports clubs (Becker and Häring 2012). Moreover, attitudes focussing on helpfulness and mutual support are highly prevalent among sports club members (Burrmann et al. 2019). In contrast, fitness studios are commercially oriented organizations, emphasizing personal counselling and individual, time-independent (cardio and weight) training. Fitness club members usually report motives that focus on body shaping, appearance and health, whereas sports club members value performance and sociability (Bakken Ulseth 2008; Molanorouzi et al. 2015). Hence, differences between the two settings relate to type of activities, underlying rationales and social context.

The higher importance of socializing and team-based activities in sports clubs compared to fitness studios can foster individual well-being. This assumption is based on ample evidence from previous studies showing that social connectedness, mutual support and recognition in social groups are major factors for individual well-being (Nguyen et al. 2016; Ronen et al. 2016; Wang 2016). Day-level data buttress these results, showing that intra-individual variations in well-being correlate with daily satisfaction of the need for relatedness (Reis et al. 2000). Based on these findings, it seems likely that an additional effect on well-being comes from the unique characteristics that pervade sports clubs (but not fitness studios). The last research question thus reads: Does participation in sports clubs relate to higher levels of life satisfaction and domain satisfaction compared to a membership in a fitness center?

\section{Methods}

\section{Study Design}

The present article is based on the German SALLSA-Study ("Sport, Active Lifestyle and Life Satisfaction"), a large-scale, cross-sectional survey. A sample $(N=1008)$, 
representing the German population ( $\geq 14$ years old), was questioned using computerassisted web interviewing (CAWI). Representativeness was accomplished by integrating the study into an existing nation-wide online panel (forsa.omninet, www.forsa.de/1 /methods/) to which access was provided by FORSA, a leading organization in public opinion polling and political consultation in Germany. A specific feature of this panel is that recruitment takes place solely offline via telephone surveys (using random digit dialling), thus assuring that population groups, who use the internet sparsely are still adequately represented in the sample. All respondents gave written consent to be contacted for this study and participated voluntarily. Respondents were invited via email to participate in the survey and were able to answer the questions on their computer, tablet, or mobile phone. The survey was designed to be answered in 20 min. Data collection took place from October 18 to November 4, 2019.

\section{Measures}

Leisure Time Sports Activity The number of hours per week is used as an indicator for LTSA. Respondents were first asked to indicate: "On how many days of a normal week do you engage in sporting activities (for instance, jogging, playing soccer, fitness exercises) during your leisure time". Those who answered " 0 " are considered nonactive. Respondents who indicated to engage in sport at least on 1 day per week were then asked to indicate the amount of LTSA in hours per week on a 8-point rating scale ranging from $1=$ "less than 1 hour per week" to $8=$ "more than 4 hours per day". Answers were recoded so that numeric values best represent a persons' engagement in LTSA in hours per week.

General Life Satisfaction To assess overall life satisfaction, we used a question established in numerous international survey programs (e.g., in the World Values Surveys): "How satisfied are you with your life as a whole". Respondents could select an answer on a 10-point Likert scale ranging from $1=$ "not at all satisfied" to $10=$ "completely satisfied".

Domain-Specific Satisfaction Satisfaction ratings were retrieved for five specific domains: 1) social relationships, 2) appearance, 3) leisure, 4) work and 5) health. For the first four domains, respondents were asked to indicate their satisfaction with the respective domain on a 10 -point Likert scale ( $1=$ "not at all satisfied" ... $10=$ "completely satisfied"). As a proxy for health satisfaction, a question on subjective health was used ("How do you rate your current state of health"). Here, respondents could also indicate their response on a 10 -point Likert scale $(1=$ "very poor".. $10=$ "excellent").

LTSA Diversity In an open question format, respondents were asked to indicate all of their regularly pursued sports activities. 622 respondents $(98.9 \%$ of all respondents actively involved in LTSA) indicated one or more activities. The measure for LTSA diversity represents the number of different sporting activities a person mentioned.

Indoor/Outdoor LTSA Respondents were asked to indicate the share of their LTSA that accounts to indoor sports and outdoor sports. Answer categories included "almost all 
outdoor sport", "mostly outdoor sport", "equal share of indoor and outdoor sport", "mostly indoor sport" and "almost all indoor sport". We calculated the variable for indoor and outdoor LTSA per week, using the hours of LTSA weighted with the share of indoor/outdoor activity.

Organizational Settings Respondents were asked if they are a member in a sports club and/or a fitness center. In both cases, they were further asked if they actively participate in activities offered by the club or the center. Based on these questions, two dummy variables were created, one for active sports club members and one for active members in fitness studios.

Socio-Demographic Variables A number of socio-demographic variables that may correlate with LTSA and well-being were included as potential confounding factors. These confounding variables included age (in years), gender (female vs. male), education (in 4 categories from lower secondary up to tertiary degrees) and personal income (in 10 categories from "no personal income" up to ">5000 €/month"). Moreover, we included dummy variables for employment (unemployed vs. employed/retired/in school), immigrant status (1st/2nd generation migrants vs. non-migrants), relationship status (partner vs. single/separated/widowed) and a question on whether a young child ( $\leq 6$ years old) lives within the household (yes vs. no).

\section{Analytical Approach}

We used linear regression models to estimate the associations between LTSA and (general and domain-specific) satisfaction ratings. A first set of models estimates a linear association between these variables, whereas a second set additionally includes the squared LTSA variable to test for non-linear effects. A third set of regression analyses includes an indicator for LTSA diversity and tests whether relationships with satisfaction are more pronounced with a greater diversity of LTSA. A fourth set of regression analyses tests whether effect sizes differ between indoor and outdoor LTSA. Finally, a last set of analyses includes the organizational context as a variable, estimating relationships for sports club and fitness studio members separately. All models include the full list of potentially confounding variables to assure that effects are robust and not spurious. All analyses were conducted using IBM SPSS 25.

\section{Results}

\section{Description of Study Sample}

Overall, 1008 participants answered the survey (51.1\% males, 48.9\% females). Respondents have a mean age of 45.0 years $(S D=17.7$, $\min =14, \max =84)$. With regard to LTSA, $38 \%$ are inactive and $62 \%$ indicated to engage in LTSA on 1 day per week, at least. The mean level of LTSA per week is $2.13 \mathrm{~h}$ (including the inactive) and $3.44 \mathrm{~h}$, when inactive individuals are excluded. General life satisfaction has its mean at 7.68 
Table 1 Descriptive statistics

\begin{tabular}{lllll}
\hline Variable & Mean & SD & min & $\max$ \\
\hline LTSA (hrs per week) & 2.13 & 2.84 & .00 & 30.00 \\
Indoor LTSA (hrs per week) & 1.17 & 1.98 & .00 & 20.00 \\
Outdoor LTSA (hrs per week) & 0.96 & 1.81 & .00 & 15.00 \\
LTSA repertoire (number of sports) & 1.33 & 1.38 & .00 & 6.00 \\
Active sport club member (dummy) & 0.22 & 0.41 & .00 & 1.00 \\
Active fitness studio member (dummy) & 0.19 & 0.39 & .00 & 1.00 \\
Life Satisfaction & 7.68 & 1.68 & 1.00 & 10.00 \\
Satisfaction with Social Relations & 7.45 & 2.37 & 1.00 & 10.00 \\
Satisfaction with Appearance & 6.64 & 1.91 & 1.00 & 10.00 \\
Satisfaction with Leisure & 7.04 & 2.01 & 1.00 & 10.00 \\
Satisfaction with Work & 7.43 & 2.19 & 1.00 & 10.00 \\
Subjective Health & 7.07 & 1.71 & 1.00 & 10.00 \\
\hline
\end{tabular}

$(S D=1.68)$. Table 1 presents further descriptions of independent and outcome variables.

\section{LTSA Effects on General and Domain-Specific Life Satisfaction}

LTSA (in hours per week) is significantly associated with general life satisfaction $(b=$ $0.08, p<.001)$. On average, $1 \mathrm{~h}$ of sport is associated with a .08-point increase in overall life satisfaction. With regard to domain satisfaction, LTSA are most important for a person's satisfaction with leisure life $(b=0.15, p<.001)$. LTSA is of lesser relevance for the health domain $(b=0.09, p<.001)$, private relationships $(b=0.07$, $p<.01)$, appearance $(b=0.07, p<.001)$ and work $(b=0.06, p<.05)$. Although LTSA has the strongest association with leisure satisfaction, it still positively relates to satisfaction in all life domains enquired (Table 2).

\section{Non-linear Relationship between LTSA and Life Satisfaction}

A further specification of the regression model includes a predictor for non-linearity, that is, the quadratic term of LTSA (Table 3). The non-linear approach leads to a significant improvement in model fit compared to a simple linear estimator in case of life satisfaction $\left(\Delta R^{2}=.004, p<.05\right)$, leisure satisfaction $\left(\Delta R^{2}=.012, p<.001\right)$ and selfrated health $\left(\Delta R^{2}=.008, p<.01\right)$. The inflection point is reached at $12 \mathrm{~h}$ (self-rated health) or $13 \mathrm{~h}$ of LTSA per week (life satisfaction, leisure satisfaction). Hence, any LTSA up to 12 or $13 \mathrm{~h}$ per week is positively related with satisfaction, whereas additional LTSA beyond that point is negatively related to it (Fig. 1).

\section{Diversity of LTSA}

A greater diversity of LTSA, measured with the number of different sports practiced by a person, yields further benefits for well-being (Table 4). The regression models show 
Table 2 Linear relationships of LTSA with general life satisfaction and domain-specific satisfaction

\begin{tabular}{|c|c|c|c|c|c|c|}
\hline & \multirow{2}{*}{$\begin{array}{l}\text { General Life } \\
\text { Satisfaction }\end{array}$} & \multicolumn{5}{|c|}{ Domain-specific satisfaction: } \\
\hline & & Relations & Appearance & Leisure & Work & Health \\
\hline LTSA (in hrs per week) & $0.08 * * *$ & $0.07 * *$ & $0.07 * * * *$ & $0.15^{* * *}$ & $0.06 *$ & $0.09 * * *$ \\
\hline Age & $0.01 *$ & $0.02 * * *$ & -0.00 & $0.02 * * *$ & $0.01 *$ & $-0.02 * * *$ \\
\hline Gender $^{1}$ & $-0.20^{+}$ & 0.14 & $-0.38 * *$ & $-0.42 * *$ & $-0.25^{+}$ & -0.06 \\
\hline Education & 0.03 & 0.09 & $0.12^{+}$ & -0.01 & $0.20 *$ & $0.14 *$ \\
\hline Personal Income & 0.03 & -0.06 & 0.04 & $-0.08 *$ & $0.09 *$ & 0.04 \\
\hline Employment Status ${ }^{2}$ & $-0.94 *$ & $-1.23 * *$ & $-0.89 *$ & -0.13 & $-2.93 * * *$ & -0.54 \\
\hline Immigrant Status & 0.14 & 0.09 & 0.08 & $0.49 *$ & -0.02 & 0.10 \\
\hline Relationship Status ${ }^{3}$ & $0.83 * * *$ & $2.43 * * *$ & $0.67 * * *$ & $0.67 * * *$ & $0.47 * *$ & $0.34 * *$ \\
\hline Young Child (ren) & -0.11 & $-0.46^{+}$ & $-0.39^{+}$ & -0.36 & -0.18 & 0.07 \\
\hline Model Fit $\left(\mathrm{R}^{2}\right)$ & .115 & .263 & .080 & .106 & .115 & .090 \\
\hline$\Delta \mathrm{R}^{2}$ (by including LTSA) ${ }^{4}$ & $.014 * * *$ & $.006 * *$ & $.010 * *$ & $.038 * * *$ & $.005 *$ & $.018 * *$ \\
\hline
\end{tabular}

${ }^{1}$ female vs. male; ${ }^{2}$ unemployed vs. employed; ${ }^{3}$ partner vs. single/separated; ${ }^{4}$ change in $\mathrm{R}^{2}$ solely by LTSA when all other variables are already included in the model

Significance: $+p<.10 ; * p<.05 ; * * p<.01 ; * * * p<.001$

that LTSA repertoire is with marginal significance positively related with life satisfaction $(b=.08, p<.10)$ and appearance satisfaction $(b=.10, p<.10)$. Moreover, LTSA diversity is positively associated with self-rated health $(b=.11, p<.05)$. The strongest relationship is found for leisure satisfaction $(b=.21, p<.001)$ : Each sporting activity that a respondent mentioned is associated with a 0.21 -point increase in leisure satisfaction.

\section{Indoor vs. Outdoor LTSA}

Another set of regression models distinguish LTSA into indoor and outdoor activity (Table 5). In these models, inactive respondents serve as the reference group for relationships of indoor respectively outdoor activity with well-being. Indoor and outdoor LTSA were positively associated with overall life satisfaction, however the

Table 3 Non-linear relationships of LTSA with general life satisfaction and domain-specific satisfaction

\begin{tabular}{|c|c|c|c|c|c|c|}
\hline & \multirow{2}{*}{$\begin{array}{l}\text { General Life } \\
\text { Satisfaction }\end{array}$} & \multicolumn{5}{|c|}{ Domain-specific satisfaction: } \\
\hline & & Relations & Appearance & Leisure & Work & Health \\
\hline LTSA (in hrs per week) & $0.133 * * *$ & $0.084^{+}$ & $0.109 * *$ & $0.265^{* * *}$ & $0.098 *$ & $0.167^{* * *}$ \\
\hline LTSA (in hrs per week squared) & $-0.005^{*}$ & -0.001 & -0.003 & $-0.010 * * *$ & -0.003 & $-0.007 * *$ \\
\hline Model Fit $\left(\mathrm{R}^{2}\right)$ & .119 & .263 & .081 & .118 & .117 & .098 \\
\hline$\Delta \mathrm{R}^{2}$ (compared to Table 2$)$ & $.004 *$ & .000 & .001 & $.012 * * *$ & .002 & $.008 * *$ \\
\hline
\end{tabular}

All controls from Table 2 are included in the models

Significance: $+p<.10 ; * p<.05 ; * * p<.01 ; * * * p<.001$ 


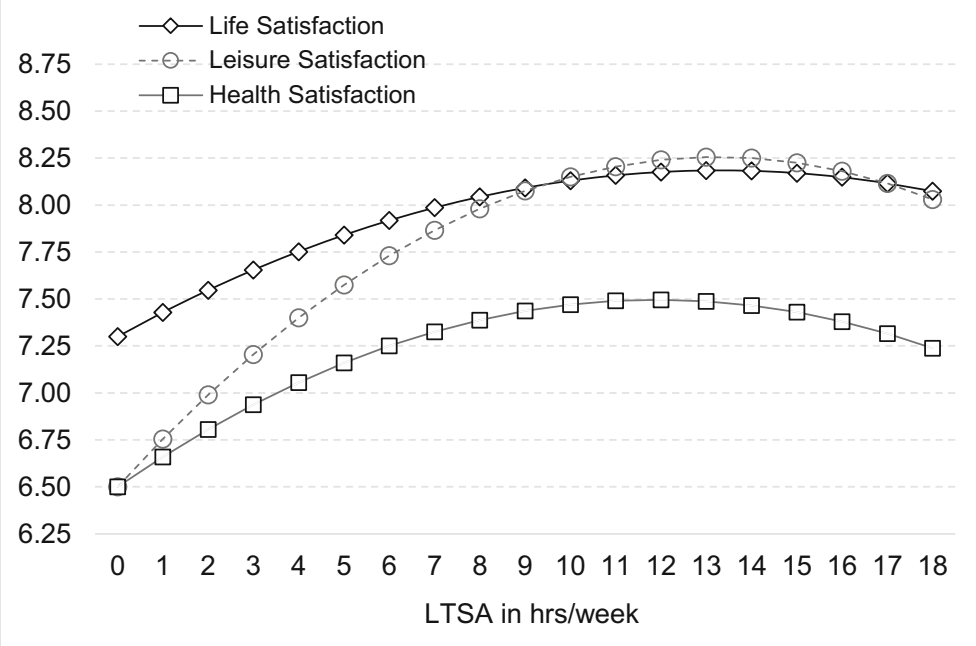

Fig. 1 Non-linear relationships of LTSA with general life satisfaction, leisure satisfaction and subjective health

association of outdoor LTSA $(b=.10, p<.01)$ is somewhat stronger compared to the association of indoor LTSA $(b=.06, p<.05)$. Similar patterns are revealed for satisfaction in the domain of leisure, where the effect of outdoor LTSA is more pronounced compared to indoor LTSA $(b=.24, p<.001$ vs. $b=.07, p<.05)$. Moreover, outdoor LTSA is significantly associated with satisfaction with social relationships $(b=.10$, $p<.05)$ and satisfaction with appearance $(b=.09, p<.05)$, whereas indoor LTSA has a significant effect on self-rated health $(b=.11, p<.001)$.

\section{Organizational Settings of LTSA}

With regard to the organizational context of LTSA, findings show that activities in sports clubs yield additional benefits for well-being (Table 6). In addition to the time spent in LTSA, active sports club members report a higher overall life satisfaction than non-members $(b=.36, p<.05)$. Moreover, active members of sports clubs also indicate substantially more leisure satisfaction $(b=.58, p<.001)$ and better subjective health

Table 4 Associations of diversity of LTSA on general life satisfaction and domain-specific satisfaction

\begin{tabular}{|c|c|c|c|c|c|c|}
\hline & \multirow{2}{*}{$\begin{array}{l}\text { General Life } \\
\text { Satisfaction }\end{array}$} & \multicolumn{5}{|c|}{ Domain-specific satisfaction: } \\
\hline & & Relations & Appearance & Leisure & Work & Health \\
\hline LTSA (in hrs per week) & $0.06 *$ & $0.06 *$ & $\mathbf{0 . 0 5}^{+}$ & $0.10 * * * *$ & $0.06^{+}$ & $0.06 *$ \\
\hline Diversity of LTSA & $0.08^{+}$ & 0.04 & $0.10^{+}$ & $0.21 * * *$ & 0.00 & $0.11 *$ \\
\hline Model Fit $\left(\mathrm{R}^{2}\right)$ & .118 & .263 & .083 & .120 & .115 & .096 \\
\hline$\Delta \mathrm{R}^{2}$ (compared to Table 2 ) & $.003^{+}$ & .000 & $.003^{+}$ & $.014 * * *$ & .000 & $.006 *$ \\
\hline
\end{tabular}

All controls from Table 2 are included in the models

Significance: $+p<.10 ; * p<.05 ; * * p<.01 ; * * * p<.001$ 
Table 5 Associations of indoor and outdoor LTSA with general life satisfaction and domain-specific satisfaction

\begin{tabular}{llllllll}
\hline & \multirow{2}{*}{$\begin{array}{l}\text { General Life } \\
\text { Satisfaction }\end{array}$} & & \multicolumn{2}{l}{ Domain-specific satisfaction: } & & \\
\cline { 4 - 7 } & & & Relations & Appearance & Leisure & Work & Health \\
\hline Indoor LTSA (in hrs per week) & $\mathbf{0 . 0 6 *}$ & 0.05 & $\mathbf{0 . 0 6}^{+}$ & $\mathbf{0 . 0 7 *}$ & 0.06 & $\mathbf{0 . 1 1} * * *$ \\
Outdoor LTSA (in hrs per week) & $\mathbf{0 . 1 0} * *$ & $\mathbf{0 . 1 0}$ & $\mathbf{0 . 0 9}^{*}$ & $\mathbf{0 . 2 4} * * *$ & 0.05 & 0.05 \\
Model Fit ( $\mathrm{R}^{2}$ ) & $\mathbf{. 1 1 7}$ & $\mathbf{. 2 6 6}$ & $\mathbf{. 0 8 2}$ & $\mathbf{. 1 1 5}$ & $\mathbf{. 1 1 6}$ & $\mathbf{. 0 9 3}$ \\
$\Delta \mathrm{R}^{2}$ (compared to Table 2) & .002 & .003 & .002 & $\mathbf{. 0 1 1} * *$ & .001 & .003 \\
\hline
\end{tabular}

All controls from Table 2 are included in the models

Significance: $+p<.10 ; * p<.05 ; * * p<.01 ; * * * p<.001$

$(b=.51, p<.001)$. Finally, they report a higher satisfaction with their appearance $(b=.33, p<.05)$ and their work $(b=.44, p<.05)$. For active members of fitness studios these associations are less pronounced and insignificant.

\section{Discussion and Conclusion}

Although a large body of literature already showed that LTSA is associated with higher well-being and life satisfaction (Wiese et al. 2018; White et al. 2017; Zhang and Chen 2019), this paper contributes to the state of knowledge by pointing out several relevant specifications of this relationship. First, we showed that the amount of LTSA is associated with life satisfaction as well as with satisfaction in the domains of leisure, appearance, social relations, work and health. The most pronounced effect was found for leisure satisfaction. This finding is in line with bottom-up conceptions of life satisfaction, postulating that leisure experiences affect leisure satisfaction directly and most strongly, whereas effects in other domains are mostly due to spill-over effects and thus less pronounced (Newman et al. 2014).

Second, the association of LTSA with regard to life satisfaction, leisure satisfaction and self-rated health is non-linear, approaching an injection point at approximately $12 \mathrm{~h}$

Table 6 Associations of organizational setting with general life satisfaction and domain-specific satisfaction

\begin{tabular}{|c|c|c|c|c|c|c|}
\hline & \multirow{2}{*}{$\begin{array}{l}\text { General Life } \\
\text { Satisfaction }\end{array}$} & \multicolumn{5}{|c|}{ Domain-specific satisfaction: } \\
\hline & & Relations & Appearance & Leisure & Work & Health \\
\hline LTSA (in hrs per week) & $0.05^{*}$ & 0.04 & $0.05^{+}$ & $0.11 * * *$ & 0.02 & $0.05^{*}$ \\
\hline Active member in sports club & $0.36^{*}$ & 0.26 & $0.33^{*}$ & $0.58 * * *$ & $0.44^{*}$ & $0.51^{* * * *}$ \\
\hline Active member in fitness centre & 0.20 & 0.26 & 0.06 & 0.16 & 0.16 & 0.14 \\
\hline Model Fit $\left(\mathrm{R}^{2}\right)$ & .123 & .266 & .084 & .118 & .122 & .104 \\
\hline$\Delta \mathrm{R}^{2}$ (compared to Table 2 ) & $.008 *$ & .003 & .004 & $.012 * *$ & $.007^{+}$ & $.014 * *$ \\
\hline
\end{tabular}

All controls from Table 2 are included in the models

Significance: $+p<.10 ; * p<.05 ; * * p<.01 ; * * * p<.001$ 
of LTSA per week. Hence, an amount of LTSA exceeding 4 to 5 times the physical activity recommendations of the WHO, is no longer beneficial for well-being. This finding is in line with the results of a large-scale accelerometer study (Bernard et al. 2018) also indicating a curvilinear relationship between average daily minutes of physical activity and mental health. In this study, increasing benefits on mental health were observed up to a limit of 50 min of physical activity per day. Pierce and Aguinis (2013) called this the "too-much-of-a-good-thing" effect, suggesting that inflection points arise after which a generally "good" activity loses this quality and desired goals go astray. Our results suggest that such an inflection point exists, however they do not allow for conclusions whether this is due to overexertion, insufficient recovery or an absence of variability in a person's leisure life.

As a third main finding, this study demonstrated that more diversity in LTSA positively relates to satisfaction ratings. Respondents who practice a broader repertoire of sporting activities are more satisfied with their life, irrespective of their overall amount of LTSA. Different sports vary with regard to typical experiences. For instance, mountain hiking in pristine nature, bodily exhaustion after a fitness class, deep concentration during yoga exercises, or playing soccer together with a group of friends may all yield very different experiential values. Given that modern individuals search for stimulating and varied recreational experiences (Elias and Dunning 1986), greater diversity in LTSA is supposed to come closer to this longing. Hence, this finding suggests that diversity in LTSA better satisfies an underlying motivation for stimulation, thereby contributing to satisfaction.

Fourth, the assumption that spatial and organisational context conditions matter found substantial support: Findings show that outdoor sports and activities in sport clubs yield additional benefits for life satisfaction and leisure satisfaction. Results with regard to satisfaction with other life domains are complex and somewhat inconsistent. These inconsistencies may be due to the broad definition of "outdoor sport" in the present study that refers to all activities in the open (e.g., including playing football or jogging) and not only to activities for which nature is a constitutive element (e.g., hiking or canoeing). Some scholars argue that it is not simply being outdoors that has a beneficial effect for well-being, but rather an immersion into nature (Kaplan, 1995). The measure of outdoor sport used in this study did not capture this latter idea of a deeper involvement into nature. More robust are findings with regard to sports clubs, where a membership is associated with a surplus in satisfaction in almost all lifedomains. Sports clubs have been described as locally rooted communities, whose culture is characterized by solidarity, volunteering and sociability (Braun 2003). Hence, social connectedness and social interactions with like-minded others are often seen as by-products of participating in sports clubs. The additional "feel good"-effect of a sports club membership may be due to these unique characteristics.

Whereas previous research often assumes that "sport" has a beneficial effect on "well-being", this study contributes to the state of knowledge, because both concepts were analysed in a more differentiated manner, uncovering important variations and finer nuances. On the one hand, it becomes obvious that the term "sport" denotes a large variety of activities - from functional training in a gym to playing football in the nearby park - which do not necessarily have the same effect on well-being. On the other hand, any sports-related associations with "well-being" can be specified with regard to general and domain satisfaction. A life domain such as "leisure" is more likely 
to be affected by LTSA than, for instance, "work" activities. Accordingly, associations vary in strength and significance, depending on the life domain analysed. Moreover, the maxim "the more the merrier" - a further implication of many previous studies (e.g., Marques et al. 2016; Richards et al. 2015) - seems to be wrong with regard to LTSA. Instead, findings suggest that the mix of the right activities in the right settings is more important for satisfaction than the mere amount of LTSA.

Besides the in-depth investigation of relationships of LTSA with life satisfaction, including the consideration of non-linear relationships, this study has some limitations. The cross-sectional data set, can describe robust associations between LTSA and wellbeing in the German population, but does not allow for conclusions on causality. Although we included the most important confounding variables in all regression models to rule out spuriousness, the direction of causality remains vague. Although interventions and longitudinal studies often demonstrated that sports have an impact on well-being (Höner and Demetriou 2012), this does not rule out the reversed causal assumption that more satisfied individuals are more likely to engage in LTSA (Baruth et al. 2011). Moreover, the self-report data on sporting activities used in the survey is prone to bias, as individuals may either overestimate their LTSA or forget to include activities that they do not pursue regularly (Boon et al. 2010).

To conclude, this study pointed to some relevant differentiations regarding the relationship between LTSA and life satisfaction. LTSA relates most strongly to leisure satisfaction and is associated with satisfaction with important life-domains in a nonlinear way. Health research is usually interested in the time spent in LTSA, however diversity of sporting activities and (environmental and organizational) context conditions also matter. These findings have implications for interventions as well as for community and school sport programs: For realizing LTSA's full potential with regard to promoting well-being, these programs should include a repertoire of diverse sports and include outdoor as well as group-based activities.

Acknowledgements Open Access funding provided by Projekt DEAL.

\section{Compliance with Ethical Standards}

Conflict of Interests The authors declare that they have no conflict of interest.

All procedures performed in this study were in accordance with the 1964 Declaration of Helsinki and its later amendments.

Informed Consent All participants in this study provide informed consent.

Open Access This article is licensed under a Creative Commons Attribution 4.0 International License, which permits use, sharing, adaptation, distribution and reproduction in any medium or format, as long as you give appropriate credit to the original author(s) and the source, provide a link to the Creative Commons licence, and indicate if changes were made. The images or other third party material in this article are included in the article's Creative Commons licence, unless indicated otherwise in a credit line to the material. If material is not included in the article's Creative Commons licence and your intended use is not permitted by statutory regulation or exceeds the permitted use, you will need to obtain permission directly from the copyright holder. To view a copy of this licence, visit http://creativecommons.org/licenses/by/4.0/. 


\section{References}

Arem, H., Moore, S. C., Patel, A., Hartge, P., Berrington de Gonzales, A., Visvanathan, K., et al. (2015). Leisure time physical activity and mortality. A detailed pooled analysis of the dose-response relationship. JAMA Internal Medicine, 175(6), 959-967.

Baker, L. A., Cahalin, L. P., Gerst, K., \& Burr, J. A. (2005). Productive activities and subjective well-being among older adults: The influence of number of activities and time commitment. Social Indicators Research, 73(3), 431-458.

Bakken Ulseth, A.-L. (2008). New opportunities - Complex motivations: Gender differences in motivation for physical activity in the context of sports clubs and fitness centers. International Journal of Applied Sports Sciences, 20(1), 44-66.

Baruth, M., Lee, D. C., Sui, X., Church, T. S., Marcus, B. H., Wilcox, S., et al. (2011). Emotional outlook on life predicts increases in physical activity among initially inactive men. Health Education \& Behavior, $38(2), 150-158$.

Becker, S., \& Häring, A. (2012). Soziale Integration durch Sport? Eine empirische Analyse zum Zusammenhang von Sport und sozialer Integration. Sportwissenschaft, 42(4), 261-270.

Bernard, P., Dore, I., Romain, A. J., Hains-Monfette, G., Kingsbury, C., \& Sabiston, C. (2018). Dose response association of objective physical activity with mental health in a representative national sample of adults: A cross-sectional study. PLoS One, 13(10), 16.

Boon, R. M., Hamlin, M. J., Steel, G. D., \& Ross, J. J. (2010). Validation of the New Zealand physical activity questionnaire (NZPAQ-LF) and the international physical activity questionnaire (IPAQ-LF) with accelerometry. British Journal of Sports Medicine, 44(10), 741-746.

Braun, S. (2003). Sozialintegration, Systemintegration und Integration über sozialstrukturelle Bindungen. In J. Baur \& S. Braun (Eds.), Integrationsleistungen von Sportvereinen als Freiwilligenorganisationen (pp. 88-108). Aachen: Meyer \& Meyer.

Brown, J. L., MacDonald, R., \& Mitchell, R. (2015). Are people who participate in cultural activities more satisfied with life? Social Indicators Research, 122(1), 135-146.

Burrmann, U., Braun, S., \& Mutz, M. (2019). Playing together or bowling alone? Social capital-related attitudes of sport club members and non-members in Germany in 2001 and 2018. European Journal for Sport \& Society, 16(2), 164-186.

Costigan, S. A., Lubans, D. R., Lonsdale, C., Sanders, T., \& Cruz, B. D. (2019). Associations between physical activity intensity and well-being in adolescents. Preventive Medicine, 125, 55-61.

Diener, E. (1984). Subjective well-being. Psychological Bulletin, 95(3), 542-575.

Dolan, P., Kavetsos, G., \& Vlaev, I. (2014). The happiness workout. Social Indicators Research, 119(3), 1363-1377.

Downward, P., \& Dawson, P. (2016). Is it pleasure or health from leisure that we benefit from most? An analysis of well-being alternatives and implications for policy. Social Indicators Research, $126(1), 443-465$.

Eijsvogels, T. M. H., Thompson, P. D., \& Franklin, B. A. (2018). The "extreme exercise hypothesis": Recent findings and cardiovascular health implications. Current Treatment Options in Cardiovascular Medicine, 20(10), 84.

Elias, N., \& Dunning, E. (1986). Quest for excitement: Sport and leisure in the civilising process. Oxford: Basil Blackwell.

Frederick, D. A., Sandhu, G., Morse, P. J., \& Swami, V. (2016). Correlates of appearance and weight satisfaction in a U.S. national sample: Personality, attachment style, television viewing, self-esteem, and life satisfaction. Body Image, 17(2), 191-203.

German Football Association (2019). Mitglieder-Statistik 2019. Electronic version: www.dfb.de/fileadmin/_ dfbdam/202541-bestandserhebung.pdf. Accessed 18.03.2020.

Giulianotti, R. (2005). Sport. A critical sociology. Cambridge: Polity Press.

Hamer, M., Stamatakis, E., \& Steptoe, A. (2009). Dose-response relationship between physical activity and mental health: The Scottish health survey. British Journal of Sports Medicine, 43(14), 1111-1114.

Hartig, T., Mang, M., \& Evans, G. W. (1991). Restorative effects of natural environment experiences. Environment and Behavior, 23(1), 3-26.

Headey, B. (2014). Bottom-up versus top-down theories of life satisfaction. In A. C. Michalos (Ed.), Encyclopedia of quality of life and well-being research (pp. 423-426). Dordrecht: Springer.

Hecht, T. D., \& Boies, K. (2009). Structure and correlates of spillover from nonwork to work: An examination of nonwork activities, well-being, and work outcomes. Journal of Occupational Health Psychology, 14(4), 414-426. 
Höner, O., \& Demetriou, Y. (2012). Körperlich-sportliche Aktivität und gesundheitsbezogene Lebensqualität. In R. Fuchs \& W. Schlicht (Eds.), Seelische Gesundheit und sportliche Aktivität (pp. 34-55). Göttingen: Hogrefe.

Hoye, R., Nicholson, M., \& Brown, K. (2012). Involvement in sport and social connectedness. International Review for the Sociology of Sport, 50(1), 3-21.

Huang, H., \& Humphreys, B. R. (2012). Sports participation and happiness: Evidence from US microdata. Journal of Economic Psychology, 33(4), 776-793.

Iso-Ahola, S. E., \& Weissinger, E. (1990). Perceptions of boredom in leisure: Conceptualization, reliability and validity of the leisure boredom scale. Journal of Leisure Research, 22(1), 1-17.

Jetzke, M., \& Mutz, M. (2019). Sport for pleasure, fitness, medals or slenderness? Differential effects of sports activities on well-being. Applied Research in Quality of Life. Online First. https://doi.org/10.1007/s11482019-09753-w.

Kaplan, S. (1992). The restorative environment: Nature and human experience. In D. Relf (Ed.), The role of horticulture in human well-being and social development (pp. 134-142). Portland: Timber Press.

Kellmann, M., Bertollo, M., Bosquet, L., Brink, M., Coutts, A. J., Duffield, R., Erlacher, D., Halson, S. L., Hecksteden, A., Heidari, J., Kallus, K. W., Meeusen, R., Mujika, I., Robazza, C., Skorski, S., Venter, R., \& Beckmann, J. (2018). Recovery and performance in sport: Consensus statement. International Journal of Sports Physiology and Performance, 13(2), 240-245.

Kuykendall, L., Tay, L., \& Ng, V. (2015). Leisure engagement and subjective well-being: A meta-analysis. Psychological Bulletin, 141(2), 364-403.

Lahart, I., Darcy, P., Gidlow, C., \& Calogiuri, G. (2019). The effects of green exercise on physical and mental well-being: A systematic review. International Journal of Environmental Research and Public Health, 16(8), 1352.

Lee, S., Koffer, R. E., Sprague, B. N., Charles, S. T., Ram, N., \& Almeida, D. M. (2018a). Activity diversity and its associations with psychological well-being across adulthood. Journal of Gerontology: Psychological Sciences, 73(6), 985-995.

Lee, H. Y., Yu, C. P., Wu, C. D., \& Pan, W. C. (2018b). The effect of leisure activity diversity and exercise time on the prevention of depression in the middle-aged and elderly residents of Taiwan. International Journal of Environmental Research and Public Health, 15(4), 654.

Lera-López, F., Ollo-López, A., \& Sánchez-Santos, J. M. (2017). How does physical activity make you feel better? The mediational role of perceived health. Applied Research in Quality of Life, 12(3), 511-531.

Marques, A., Peralta, M., Martins, J., Catunda, R., de Matos, M. G., \& Nunes, L. S. (2016). Associations between physical activity and self-rated well-being in European adults: A population-based, crosssectional study. Preventive Medicine, 91(1), 18-23.

Mason, P., Curl, A., \& Kearns, A. (2016). Domains and levels of physical activity are linked to adult mental health and well-being in deprived neighbourhoods: A cross-sectional study. Mental Health and Physical Activity, 11(1), 19-28.

McMahon, E. M., Corcoran, P., O’Regan, G., Keeley, H., Cannon, M., Carli, V., Wasserman, C., Hadlaczky, G., Sarchiapone, M., Apter, A., Balazs, J., Balint, M., Bobes, J., Brunner, R., Cozman, D., Haring, C., Iosue, M., Kaess, M., Kahn, J. P., Nemes, B., Podlogar, T., Poštuvan, V., Sáiz, P., Sisask, M., Tubiana, A., Värnik, P., Hoven, C. W., \& Wasserman, D. (2017). Physical activity in European adolescents and associations with anxiety, depression and well-being. European Child \& Adolescent Psychiatry, 26(1), $111-122$.

Mnich, C., Weyland, S., Jekauc, D., \& Schipperijn, J. (2019). Psychosocial and physiological health outcomes of green exercise in children and adolescents - a systematic review. International Journal of Environmental Research and Public Health, 16(21), 4266.

Molanorouzi, K., Khoo, S., \& Morris, T. (2015). Motives for adult participation in physical activity: Type of activity, age, and gender. BMC Public Health, 15, 66.

Mutz, M., \& Müller, J. (2016). Mental health benefits of outdoor adventures: Results from two pilot studies. Journal of Adolescence, 49(1), 105-114.

Newman, D. B., Tay, L., \& Diener, E. (2014). Leisure and subjective well-being: A model of psychological mechanisms as mediating factors. Journal of Happiness Studies, 15(3), 555-578.

Nguyen, A. W., Chatters, L. M., Taylor, R. J., \& Mouzon, D. M. (2016). Social support from family and friends and subjective well-being of older african americans. Journal of Happiness Studies, 17(3), 959-979.

Pierce, J. R., \& Aguinis, H. (2013). The too-much-of-a good-thing effect in management. Journal of Management, 39(2), 313-338.

Reis, H. T., Sheldon, K. M., Gable, S. L., Roscoe, J., \& Ryan, R. M. (2000). Daily well-being: The role of autonomy, competence, and relatedness. Personality and Social Psychology Bulletin, 26(4), 419-435. 
Richards, J., Jiang, X., Kelly, P., Chau, J., Bauman, A., \& Ding, D. (2015). Don’t worry, be happy: Crosssectional associations between physical activity and happiness in 15 European countries. BMC Public Health, 15, 53.

Ronen, T., Hamama, L., Rosenbaum, M., \& Mishely-Yarlap, A. (2016). Subjective well-being in adolescence: The role of self-control, social support, age, gender, and familial crisis. Journal of Happiness Studies, 17(1), 81-104.

Schell, L., Cotton, S., \& Luxmoore, M. (2012). Outdoor adventure for young people with a mental illness. Early Intervention in Psychiatry, 6(4), 407-414.

Schimmack, U. (2008). The structure of subjective well-being. In M. Eid \& R. J. Larsen (Eds.), The science of subjective well-being (pp. 97-123). New York: Guilford Press.

Schulz, P., Schulte, J., Raube, S., Disouky, H., \& Kandler, C. (2018). The role of leisure interest and engagement for subjective well-being. Journal of Happiness Studies, 19(4), 1135-1150.

Sigvartsen, J., Gabrielsen, L. E., Abildsnes, E., Stea, T. H., Omfjord, C. S., \& Rohde, G. (2016). Exploring the relationship between physical activity, life goals and health-related quality of life among high school students: A cross-sectional study. BMC Public Health, 16, 709.

Sirgy, M. J., Uysal, M., \& Kruger, S. (2017). Towards a benefits theory of leisure well-being. Applied Research in Quality of Life, 12(1), 205-228.

Stalker, G. J. (2011). Leisure diversity as an indicator of cultural capital. Leisure Sciences, 33(2), 81-102.

Thompson Coon, J., Boddy, K., Stein, K., Whear, R., Barton, J., \& Depledge, M. H. (2011). Does participating in physical activity in outdoor natural environments have a greater effect on physical and mental well-being than physical activity indoors? A systematic review. Environmental Science and Technology, 45(5), 1761-1772.

Wang, X. (2016). Subjective well-being associated with size of social network and social support of elderly. Journal of Health Psychology, 21(6), 1037-1042.

White, R. L., Babic, M. J., Parker, P. D., Lubans, D. R., Astell-Burt, T., \& Lonsdale, C. (2017). Domainspecific physical activity and mental health: A meta-analysis. American Journal of Preventive Medicine, 52(5), 653-666.

Wienke, B., \& Jekauc, D. (2016). A qualitative analysis of emotional facilitators in exercise. Frontiers in Psychology, 7, 1296.

Wiese, C. W., Kuykendall, L., \& Tay, L. (2018). Get active? A meta-analysis of leisure-time physical activity and subjective well-being. Journal of Positive Psychology, 13(1), 57-66.

Zhang, Z., \& Chen, W. (2019). A systematic review of the relationship between physical activity and happiness. Journal of Happiness Studies, 20(4), 1305-1313.

Publisher's Note Springer Nature remains neutral with regard to jurisdictional claims in published maps and institutional affiliations. 